\title{
DIETARY PATTERNS OF ADULTS WITH ASTHMA TREATED AT A REFERRAL CENTER FOR ASTHMA
}

\author{
Gabriele Carra Forte ${ }^{1,2}$, Cristina Carra Forte ${ }^{3,4}$, Maria Luiza Torres \\ Hennemann ${ }^{5}$, Luiza Tweedie Preto ${ }^{5}$, Jussara Carnevale Almeida ${ }^{5,6}$, \\ Paulo de Tarso Roth Dalcin ${ }^{7,8}$, Raquel Canuto ${ }^{5}$
}

\begin{abstract}
Introduction: Consumption of foods with anti-inflammatory and antioxidant components could contribute to a better control of the asthma. The aim of this study was to assess the association between dietary patterns, nutritional status, and asthma control in patients treated at an asthma referral center in Porto Alegre, Brazil.
\end{abstract}

Methods: This is a cross-sectional study with 198 adult asthma patients. Participants completed a 24-hour food recall and a questionnaire on disease history, degree of control, and severity, as well as pulmonary and anthropometric assessments. We used exploratory factor analysis and principal component analysis as an extraction method to derive the dietary patterns.

Results: The mean body mass index was 29.6 (SD, 5.7) $\mathrm{kg} / \mathrm{m}^{2}$, and $41.9 \%$ were classified as obese. Regarding disease severity, $72.7 \%$ were classified as having severe persistent asthma, and concerning the degree of control, $59.6 \%$ of the patients had uncontrolled asthma. Three dietary patterns were identified: "Sugars", "Healthy", and "Fats and Alcohol". It was observed that the Fats and Alcohol pattern was significantly associated with men. However, no associations were observed between the other variables and dietary patterns.

Conclusion: This was the first study to identify the dietary patterns in asthmatics in Brazil. Patterns found in the present study were "Sugars", "Healthy" and "Fats and Alcohol". However, there was no significant association between the 3 patterns and nutritional status or disease control.

Keywords: Asthma; Feeding behavior; Nutritional status

\section{INTRODUCTION}

Asthma is a chronic inflammatory disease of the airways, characterized by respiratory symptoms, bronchial hyperresponsiveness, and reversible airflow limitation ${ }^{1}$. The World Health Organization (WHO) estimates that asthma affects 300 million people worldwide, including children and adults ${ }^{2}$. In Brazil, it affects 6.4 million people over the age of 18, accounting in 2014 for 105,500 hospital admissions, resulting in a public health cost of $\$ 57.2$ million $^{3}$.

The pathogenesis of asthma is complex and not fully understood. However, overweight has been considered an important risk factor for adults with asthma ${ }^{4,5}$. On the one hand, studies show that individuals with persistent asthma tend to perform fewer physical activities due to functional limitation, which reduces caloric expenditure and leads to overweight and obesity in the long term ${ }^{6}$; on the other hand, there is asthma severity and a worsening of symptoms when there is an increase in body mass index $(\mathrm{BMI})^{7,8}$.

Similarly, the relationship between diet and the development and control of asthma has not yet been elucidated. It is known that the consumption of foods with anti-inflammatory and antioxidant components ${ }^{9}$ could contribute to
Clin Biomed Res. 2021;41(4):275-282

1 Escola de Medicina, Pontifícia Universidade Católica do Rio Grande do Sul. Porto Alegre, RS, Brasil.

2 Departamento de Nutrição, Hospital de Clínicas de Porto Alegre. Porto Alegre, RS, Brasil.

3 Programa de Pós-graduação em Medicina e Ciências da Saúde, Pontifícia Universidade Católica do Rio Grande do Sul. Porto Alegre, RS, Brasil.

4 Departamento de Nutrição, Hospital Nossa Senhora da Conceição. Porto Alegre, RS, Brasil.

5 Departamento de Nutrição, Universidade Federal do Rio Grande do Sul. Porto Alegre, RS, Brasil.

6 Programa de Pós-graduação em Endocrinologia, Universidade Federal do Rio Grande do Sul. Porto Alegre, RS, Brasil.

7 Programa de Pós-graduação em Ciências Pneumológicas, Universidade Federal do Rio Grande do Sul. Porto Alegre, RS, Brasil.

8 Serviço de Pneumologia, Hospital de Clínicas de Porto Alegre. Porto Alegre, RS, Brasil.

Corresponding author: Gabriele Carra Forte gabicarraforte@yahoo.com.br Escola de Medicina, Pontifícia Universidade Católica do Rio Grande do Sul; Hospital de Clínicas de Porto Alegre

Rua General Lima e Silva, 148, apto 405, Bloco A, 90050-100, Porto Alegre, RS, Brasil. 
Forte et al.

a better control of the disease ${ }^{10,11}$. However, studies on dietary patterns, derived from factor analysis or cluster analysis, are relatively new, mainly in adults ${ }^{12}$. Nutritional epidemiology has recommended that the dietary pattern of individuals and the population should be evaluated, and that nutrient intakes should not be assessed separately, especially when studying noncommunicable chronic diseases ${ }^{13}$.

Among the studies that used this approach, 3 found positive associations between dietary intake and asthma development with dietary patterns "Meat and Cheese" (red meat, processed meat, and cheese) ${ }^{14}$, "Traditional" (rice, vegetables, and wheat flour) ${ }^{15}$, and "Rich in Fat, Salt, and Sugar" (bakery, chocolate, desserts, pastries, chips, fruit juice, soft drinks, and alcoholic beverages) ${ }^{16}$, and 2 found negative associations with "Cheese and whole-grain Bread" (high intake of these foods) ${ }^{14}$ and "Fish, Fruits and Vegetables" (high intake) ${ }^{16}$.

Thus, this study aimed to identify dietary patterns of asthma patients treated at the asthma clinic of the Hospital de Clínicas de Porto Alegre and its relation to nutritional status and disease control.

\section{METHODS}

This was a cross-sectional study with 198 adult asthmatic patients treated at the asthma clinic of the Pulmonology Service of the Hospital de Clínicas de Porto Alegre.

Patients were referred to the outpatient clinic and diagnosed with asthma according to the guidelines of the Brazilian Society of Pulmonology and Asthma Physiology for Asthma Management ${ }^{1}$. Smoking patients with a smoking index $>10$ pack-years, patients diagnosed with another chronic pulmonary disease, such as chronic obstructive pulmonary disease, bronchiectasis, and diffuse pulmonary disease, those diagnosed with human immunodeficiency virus infection or disabling neurological disease, and those who did not complete the assessments proposed by the study were excluded. Sociodemographic information and clinical data on the disease were collected using a structured questionnaire.

The clinical asthma outcomes were assessed by severity, degree of control, and pulmonary function. The degree of asthma control was assessed according to the Global Initiative for Asthma (GINA) ${ }^{17}$, classifying patients into controlled, partially controlled, and uncontrolled asthma. The severity of the disease was classified according to the drug regimen used and the response to treatment was classified according to GINA $^{17}$, in mild persistent asthma, moderate persistent asthma, and severe persistent asthma ${ }^{17}$. The spirometric evaluation was performed using the Jaeger, version 4.31a (Jaeger, Wuerzburg, Germany), and 3 successive forced expiratory curves were performed and recorded at higher values. Forced expiratory volume in the first second $\left(F E V_{1}\right)$ and forced vital capacity ( $F V C$ ), in liters and percentage of predicted, were recorded in $\mathrm{FEV}_{1} / \mathrm{FVC}$ in absolute value and percentage of predicted values ${ }^{18}$. For analysis, this variable was categorized as: $\mathrm{FEV}_{1}>80 \%$; $\mathrm{FEV}_{1}$ $60-80 \% ;<60 \%{ }^{19}$.

In the anthropometric evaluation, weight and height measurements were performed to calculate the BMI. The cutoff points for BMI were: normal weight ( 18.5 to $24.9 \mathrm{~kg} / \mathrm{m}^{2}$ ), overweight ( 25 to $29.9 \mathrm{~kg} / \mathrm{m}^{2}$ ), and obese $\left(\geq 30 \mathrm{~kg} / \mathrm{m}^{2}\right)$. To measure weight $(\mathrm{kg})$, the patient had to stand in the center of the scale, wearing light clothing. The electronic scale used was a high precision Urano $®$ model that supports up to $150 \mathrm{~kg}$, with a $50 \mathrm{~g}$ variation. Height was measured in meters using a Tonelli \& Gomes ${ }^{\circledR}$ stadiometer, fixed to a smooth wall without skirting, with a movable rod, graduated in centimeters and millimeters.

To assess food consumption, a 24-hour recall (R24h) was used, administered by trained professionals. The patients reported their food consumption on the day before the interviews and the amount of each item of food consumed in household measures. The reported home measurements were transformed into grams/food ${ }^{20,21}$.

To determine the dietary patterns, the food items were first grouped into food groups according to the frequency of consumption and nutritional similarity. Food items with an intake of less than $5 \%$ were excluded from the analysis.

We conducted a principal components factor analysis (PCA) to derive major dietary patterns. The reliability of the factor analysis procedure was assessed via the Kaiser-Meyer-Olkin statistics (coefficient reference: $\mathrm{KMO} \geq 0.8$ ) and the Bartlett test of sphericity (reference: $p \leq 0.05$ ). The factors were rotated by an orthogonal (Varimax) transformation. The number of factors retained was based on the following criteria: components with an eigenvalue of $>1$, scree plot test, and the interpretability of the factors.

The eigenvalues signify the amount of variance explained by each of the factors. Food items were considered to load on a factor if they had an absolute correlation $\geq 0.30$ with the factor and thus were retained in the calculations of the dietary pattern scores.

The dietary patterns were analyzed as continuous variables. The associations between the other variables and the dietary patterns were tested using Student's $t$ test and ANOVA. Significance was set at $5 \%$ in all analyses. Statistical analyses were performed in SPSS, version 18. According to the rule proposed by Hair $^{22}$ to identify dietary patterns using principal component analysis, the required sample size would be 140 individuals $(28$ food items $\times 5$ ). 
The Research Ethics Committee of the Hospital de Clínicas de Porto Alegre approved the research under number 12.0103 , and all participants signed the Informed Consent Form.

\section{RESULTS}

After applying the exclusion and inclusion criteria to the 344 asthmatic patients in the target population from March to November 2013, a total of 71 individuals were not eligible and 75 were recruited to participate in the study. Thus, 198 individuals were included in the final sample of this study.
The final sample consisted of individuals with a mean age of 56.2 (SD, 14.8 years). There was a predominance of women $(81.8 \%)$ and individuals who declared themselves to be white $(75.3 \%)$. The mean BMI was 29.6 (SD, 5.7) $\mathrm{kg} / \mathrm{m}^{2}, 21.7 \%$ of the subjects were classified as eutrophic, $36.4 \%$ were overweight, and $41.9 \%$ were obese. Regarding the severity of the disease, $11.6 \%$ were classified as having mild persistent asthma, $15.7 \%$ moderate persistent asthma, and $72.7 \%$ severe persistent asthma. Regarding the degree of control, $59.6 \%$ of patients had uncontrolled asthma, $14.1 \%$ partially controlled, and $26.3 \%$, controlled. The characteristics of the sample are shown in Table 1.

Table 1: General characteristics of patients with asthma.

\begin{tabular}{|c|c|}
\hline Variables & $N=198$ \\
\hline \multicolumn{2}{|l|}{ Sex, n (\%) } \\
\hline Female & $162(81.8)$ \\
\hline Male & $36(18.2)$ \\
\hline Age (years), mean $\pm S D$ & $56.2 \pm 14.8$ \\
\hline \multicolumn{2}{|l|}{ Ethnicity, n (\%) } \\
\hline White & $150(75.3)$ \\
\hline Other & $48(24.2)$ \\
\hline Age at diagnosis (years), median (IQR) & $20.5(44)$ \\
\hline \multicolumn{2}{|l|}{ Smoking status, n (\%) } \\
\hline Never & $138(69.7)$ \\
\hline Former & $60(30.3)$ \\
\hline Comorbidities, n (\%) & $125(63.1)$ \\
\hline Allergic Rhinitis, n (\%) & $141(71.2)$ \\
\hline \multicolumn{2}{|l|}{ GINA severity classification, n (\%) } \\
\hline Mild & $23(11.6)$ \\
\hline Moderate & $31(15.7)$ \\
\hline Severe & $144(72.7)$ \\
\hline \multicolumn{2}{|l|}{ GINA asthma control, n (\%) } \\
\hline Controlled & $52(26.3)$ \\
\hline Partly controlled & $28(14.1)$ \\
\hline Uncontrolled & $118(59.6)$ \\
\hline BMI $\left(\mathrm{kg} / \mathrm{m}^{2}\right)$, mean \pm SD & $29.6 \pm 5.7$ \\
\hline \multicolumn{2}{|l|}{ Nutritional status, n (\%) } \\
\hline Normal weight & $43(21.7)$ \\
\hline Overweight & $72(36.4)$ \\
\hline Obese & $83(41.9)$ \\
\hline \multicolumn{2}{|c|}{ Pulmonary Function (pre-bronchodilator), mean \pm SD } \\
\hline FVC (L) & $2.5 \pm 0.9$ \\
\hline FVC \% predicted & $81.2 \pm 21.3$ \\
\hline FEV1 (L) & $1.7 \pm 0.7$ \\
\hline FEV1 \% predicted & $68.2 \pm 22.2$ \\
\hline FEV1/FVC \% predicted & $82.1 \pm 13.0$ \\
\hline
\end{tabular}

$\mathrm{N}$ : number of cases (\% total cases); SD: standard deviation; IQR: interquartile range; GINA: Global Initiative for Asthma; BMI: body mass index; FVC: forced vital capacity; FEV $_{1}$ : forced expiratory volume in $1 \mathrm{~s}$. 
The food items and the frequency of consumption after grouping are shown in Table 2. A total of 28 food groups were formed from the 142 items recorded on the R24h. Three dietary patterns were identified that accounted for $22.84 \%$ of the total variance explained, as shown in Table 3. Pattern 1, called Sugars was associated with a higher intake of biscuits and cakes, pasta, bread, coffee and tea, soda and powdered juice, sugar, and fast food. Pattern 2 was classified as Healthy, positively charged for white meats, juices, citrus fruits, other fruits, dark green vegetables, cruciferous vegetables, yellow vegetables, other vegetables, white rice, beans, bananas, apples, and whole grains. And lastly, pattern 3, Fats and Alcohol, was associated with the increased intake of whole grains, tubers, milk and dairy products, red meats, sausages, margarine and mayonnaise, butter and sour cream, and sweets and alcohol.

Table 2: Final food items and absolute and relative consumption frequency in individuals.

\begin{tabular}{|c|c|c|}
\hline Food Items & $\mathbf{N}$ & $\%$ \\
\hline Milk and dairy products & 152 & 76.8 \\
\hline White rice & 141 & 71.2 \\
\hline Red meat & 122 & 61.6 \\
\hline Breads & 120 & 60.6 \\
\hline Coffee and tea & 118 & 59.6 \\
\hline Sugar & 98 & 49.5 \\
\hline Other vegetables & 94 & 47.5 \\
\hline Soda and powder juice & 92 & 42.5 \\
\hline Dark green vegetables & 84 & 42.4 \\
\hline Beans & 79 & 39.9 \\
\hline White meat & 69 & 34.2 \\
\hline Biscuit and cakes & 66 & 33.3 \\
\hline Margarine mayonnaise & 64 & 32.3 \\
\hline Banana & 59 & 29.8 \\
\hline Sweets & 58 & 29.3 \\
\hline Whole grains & 55 & 27.8 \\
\hline Sausages & 54 & 27.3 \\
\hline Juices & 50 & 25.3 \\
\hline Citrus fruits & 45 & 22.7 \\
\hline Tubers & 39 & 19.7 \\
\hline Other fruits & 35 & 17.7 \\
\hline Apple & 32 & 16.2 \\
\hline Pastas & 28 & 14.1 \\
\hline Crucifers & 26 & 13.1 \\
\hline Butter and milk cream & 25 & 12.6 \\
\hline Fast foods & 19 & 9.6 \\
\hline Alcohol & 10 & 5.0 \\
\hline
\end{tabular}

Table 3: Food patterns identified, food items and factorial loads that compose them and percentage of variance explained.

\begin{tabular}{lcc}
\hline & Food Items & Dietary patterns \\
\cline { 2 - 3 } & Sugars & Healthy \\
\hline Sugar & 0.630 & \\
Soda and powder juice & 0.586 & \\
Coffee and tea & 0.507 & \\
Breads & 0.386 & \\
Fast food & 0.150 & \\
Biscuit and cakes & 0.106 & \\
Pastas & 0.044 & \\
Vegetable dark green & & 0.638 \\
Beans & & 0.616 \\
Banana & & 0.536 \\
Juices & & 0.520 \\
White rice & & 0.520 \\
Other vegetables & & 0.416 \\
Apple & & 0.415 \\
\hline
\end{tabular}


Table 3: Continue

\begin{tabular}{|c|c|c|c|}
\hline \multirow{2}{*}{ Food Items } & \multicolumn{3}{|c|}{ Dietary patterns } \\
\hline & Sugars & Healthy & Fats and Alcohol \\
\hline Whole grains & & 0.289 & 0.308 \\
\hline Crucifers & & 0.115 & \\
\hline White meat & & 0.051 & \\
\hline Citrus fruits & & 0.042 & \\
\hline Yellow vegetables & & 0.042 & \\
\hline Other fruits & & 0.001 & \\
\hline Red meat & & & 0.642 \\
\hline Sausages & & & 0.529 \\
\hline Alcohol & & & 0.506 \\
\hline Milk and dairy products & & & 0.426 \\
\hline Margarine and mayonnaise & & & 0.266 \\
\hline Butter and milk cream & & & 0.185 \\
\hline Tubers & & & 0.165 \\
\hline Sweets & & & 0.101 \\
\hline$\%$ cumulative variance & 8.35 & 16.52 & 22.84 \\
\hline
\end{tabular}

Table 4 shows the means and respective standard deviations of the association between consumption of dietary patterns and demographic variables, nutritional status, and asthma control.
It was observed that the Fat and Alcohol pattern was significantly associated with men. No associations were observed between the other variables and dietary patterns.

Table 4: Means and standard deviations of the associations between dietary patterns and demographic variables, nutritional status, and asthma control.

\begin{tabular}{|c|c|c|c|c|c|c|}
\hline & \multicolumn{6}{|c|}{ Dietary patterns } \\
\hline & \multicolumn{2}{|l|}{ Sugars } & \multicolumn{2}{|l|}{ Healthy } & \multicolumn{2}{|c|}{ Fats and Alcohol } \\
\hline & Mean ( \pm SD) & p-value & Mean ( \pm SD) & p-value & Mean ( \pm SD) & p-value \\
\hline Sex & & $0.937^{*}$ & & $0.496^{*}$ & & $<0.001^{*}$ \\
\hline Male & $0.012(0.925)$ & & $0.103(1.446)$ & & $0.641(1.315)$ & \\
\hline Female & $-0.002(1.018)$ & & $-0.022(0.875)$ & & $-0.142(0.857)$ & \\
\hline Age (years) & & $0.077^{* *}$ & & $0.350^{* *}$ & & $0.853^{* *}$ \\
\hline$<46$ & $0.240(0.889)$ & & $-0.036(1.307)$ & & $0.026(0.916)$ & \\
\hline $47-57$ & $0.050(1.013)$ & & $-0.143(0.728)$ & & 0.038 (1.369) & \\
\hline $58-65$ & $0.018(1.242)$ & & $0.213(1.141)$ & & $-0.113(0.876)$ & \\
\hline$>66$ & $-0.274(0.774)$ & & $-0.017(0.756)$ & & $0.040(0.727)$ & \\
\hline Nutritional status & & $0.835^{\star}$ & & $0.824^{\star *}$ & & $0.299^{* *}$ \\
\hline Normal & $0.073(0.931)$ & & $0.082(1.475)$ & & $-0.089(0.846)$ & \\
\hline Overweight & $0.002(1.043)$ & & $-0.033(0.775)$ & & $0.146(1.135)$ & \\
\hline Obese & $-0.039(1.005)$ & & $-0.013(0.873)$ & & $-0.080(0.943)$ & \\
\hline GINA asthma control & & $0.331^{* *}$ & & $0.117^{* *}$ & & $0.163^{* *}$ \\
\hline Controlled & $-0.165(0.841)$ & & $0.026(0.918)$ & & $0.166(1.375)$ & \\
\hline Partly controlled & $0.149(1.223)$ & & $0.340(1.558)$ & & $0.161(0.789)$ & \\
\hline Uncontrolled & $0.037(1.005)$ & & $-0.092(0.847)$ & & $-0.111(0.827)$ & \\
\hline GINA severity & & $0.243^{* *}$ & & $0.406^{\star *}$ & & $0.854^{* *}$ \\
\hline Mild & $-0.300(0.989)$ & & $-0.114(0.699)$ & & $-0.052(1.456)$ & \\
\hline Moderate & $-0.746(0.898)$ & & 0.212 (1.205) & & $0.087(0.828)$ & \\
\hline Severe & $0.064(1.018)$ & & $-0.027(0.992)$ & & $-0.010(0.951)$ & \\
\hline Pulmonary function $\left(\mathrm{FEV}_{1}\right)$ & & $0.608^{* *}$ & & $0.430^{* *}$ & & $0.257^{* *}$ \\
\hline$<60 \%$ & $0.088(1.132)$ & & -0.029 (0855) & & $-0.132(1.114)$ & \\
\hline $60-80 \%$ & $-0.032(0.831)$ & & $0.125(1.070)$ & & $0.146(0.995)$ & \\
\hline$>80 \%$ & $-0.078(0.998)$ & & $-0.102(1.091)$ & & $0.006(0.827)$ & \\
\hline
\end{tabular}

SD: standard deviation; $\mathrm{FEV}_{1}$ : forced expiratory volume in $1 \mathrm{~s}$.

* Student's $t$ test; **ANOVA 


\section{DISCUSSION}

This study, conducted in asthmatic patients treated at a reference center in the municipality of Porto Alegre, identified 3 eating patterns: Sugars, Healthy, and Fat and Alcohol. The Fats and Alcohol pattern was associated with men. However, no association was observed between the 3 dietary patterns and the nutritional status, pulmonary function, and degree of disease control in these patients.

The patterns found in this study are similar to the patterns found in other studies with asthmatic populations, especially in the study by Shi et al. ${ }^{15}$, who identified 4 patterns: Male, characterized by meat and alcohol; Traditional, with high rice and vegetable intake; Sugar, rich in cakes, milk, yogurt, and sugary drinks; and Rich in Vegetables, with high consumption of whole grains, fruits, tubers, vegetables, milk, eggs, and fish. Lv et al. ${ }^{12}$ performed a meta-analysis to analyze eating patterns and categorized 3 patterns: Healthy, characterized by high consumption of fruit, vegetables, whole grains, and/or fish; Unhealthy, characterized by a high quantity of refined grains, red meat, processed meat, fast food, foods rich in sugar and/or fat; and Neutral, consisting of the combination of the 2 previous patterns. Thus, the Healthy pattern found in our study resembles the homonymous pattern stipulated by the authors of this meta-analysis, and the combination of the Sugars and Fats and Alcohol patterns in our study resembles the Unhealthy pattern also stipulated by them.

In addition to this meta-analysis, other authors ${ }^{10,12,14,23,24}$ also found in their studies a healthy pattern characterized by a high intake of fruits, vegetables, whole grains, and fish. The sugar pattern found in the present study was similar to that found in the studies by Shi et al. ${ }^{15}$ and Barros et al. ${ }^{16}$, where the most positively charged foods were soft drinks, processed juices, bakery foods, cakes, sweets, desserts, and chocolate. The Fats and Alcohol pattern was similar to that found in the studies by Shi et al. ${ }^{15}$, Hooper et al. ${ }^{24}$, Bakolis et al. ${ }^{23}$, Rosenkranz et al. ${ }^{14}$, and McKeever et al. ${ }^{11}$ consisting mainly of red meat, bacon, sausage, and fat added to food and alcohol.

Dietary patterns in asthmatic individuals also appear to be associated with sex. Rosenkranz et al. ${ }^{14}$ analyzed the dietary patterns of men and women separately, and a positive association was observed between the pattern Meat and Cheese in men and a negative association of the pattern Cheese and Whole bread in women. Similar results to the present study were observed by McKeever et al. ${ }^{11}$, who verified that the Cosmopolitan pattern (high consumption of vegetables, fish, chicken, wine, and rice) was associated with women and the Traditional pattern (characterized by red meat, processed meat, potatoes, cooked vegetables, added fat to foods, coffee, and beer) was associated with men. According to Vigitel $2014^{25}$, overweight is higher among men. In addition, regular consumption of soft drinks, whole milk fat, and meat with excess fat is higher among men. On the other hand, women consume more fruit and vegetables.

Similar to the present study, Bakolis et al. ${ }^{23}$, Lv et al. ${ }^{12}$, and Hooper et al. ${ }^{24}$ found no significant associations between asthma outcomes and the eating patterns assessed. However, control of the disease seems to be important in relation to the pattern of food consumption among these individuals, since other studies have shown positive associations between eating patterns and asthma, such as Meat and Cheese (red meat, processed meat, and cheese) ${ }^{14}$, Traditional (rice, vegetables, and wheat flour) ${ }^{15}$, and Rich in Fat, Sugar, and Salt (bakery, chocolate, desserts, pastries, chips, fruit juice, soft drinks, and alcoholic beverages $)^{16}$. Varraso et al. ${ }^{10}$ observed that the Nuts and Wine pattern was negatively associated with the risk of asthma attacks, whereas in the Western pattern this risk is significantly increased. In addition, McKeever et al. ${ }^{11}$ observed an association between the Traditional pattern and lower pulmonary function. On the other hand, other authors have described some dietary patterns as protective for asthma: the food patterns Cheese and Whole Grains ${ }^{14}$ and Fish, Fruits, and Vegetables ${ }^{16}$.

In general, dietary patterns positively associated with asthma can be classified as calorie-rich and nutrient-poor, which is also associated with a high score of disease symptoms and increased prevalence of asthma in children ${ }^{26}$. The increased consumption of omega- 6 polyunsaturated fatty acids and the reduction of omega-3 polyunsaturated fatty acids have contributed to the increase in cases of the disease. This demonstrates an important role of fatty acid intake in modulating inflammation and may explain the protective effect of omega- 3 on the disease ${ }^{27}$. According to Bidad et al. ${ }^{28}$, the type of fat ingested seems to be more important than the amount of fat.

In addition to fat, other aspects of the relationship between diet and development and control of the disease can already be described, such as a low intake of dietary antioxidants, which can be a risk factor for asthma, together with the important role of sodium, potassium, and magnesium in the development of the disease, since asthma is associated with an important oxidative imbalance, and the antioxidant levels affect the risk of the disease by influencing the immune response to allergen provocation or inflammatory response ${ }^{29}$. Studies have already shown that a diet containing fruit and fish is related to a lower incidence of asthma ${ }^{30,31}$, and diets restricted in fruits and vegetables are related to an increase in the symptoms characteristic of the disease ${ }^{32-35}$. In addition, wine and oilseeds also 
appear to have an important protective effect, which can be explained by the large amount of vitamin $E$ and selenium found in oleaginous plants, preventing oxidative stress ${ }^{29,36}$, and flavonoids, especially when coming from apple ${ }^{37}$ and red wine ${ }^{38}$.

The present study has some limitations. The crosssectional design does not allow for the assessment of temporality between cause and effect. Also, the sample size, although adequate for identifying eating patterns, may not have been able to detect associations between eating patterns and other explanatory variables. Finally, the present study used $\mathrm{R} 24 \mathrm{~h}$ to assess food intake. This instrument may not be able to measure the habitual food consumption of individuals.

Identifying eating patterns that play a protective role in asthma symptomatology and development is of utmost importance since individuals do not consume nutrients alone and the food combination contains numerous substances and interactions between nutrients, which a nutrient-only analysis may not detect $^{35}$. In addition, nutritional recommendations are based on foods and their combinations.

Although there were no significant associations between the 3 patterns found and the nutritional status or disease control in this study, we recommended the adoption of a healthy dietary pattern, consuming natural and the least processed foods possible, to obtain the amounts and qualities of micronutrients important for overall health, prevention and control of asthma, and to avoid excessive weight gain, which is an important risk factor for asthma and other chronic noncommunicable diseases. Furthermore, additional studies focusing on the relationship between dietary intake and clinical outcomes of asthma are also recommended.

\section{REFERENCES}

1. Sociedade Brasileira de Pneumologia e Tisiologia. Diretrizes da Sociedade Brasileira de Pneumologia e Tisiologia para o Manejo da Asma. J Bras Pneumol. 2012;38(Supl 1):S1-46.

2. World Health Organization. Chronic respiratory diseases: asthma [Internet]. Geneva: WHO; 2020 [updated 2021 May 3; cited 2021 Out 8]. Available from: https://www. who.int/news-room/q-a-detail/chronicrespiratory-diseases-asthma

3. Instituto Brasileiro de Geografia e Estatística. Pesquisa Nacional de Saúde 2013: acesso e utilização dos serviços de saúde, acidentes e violências: Brasil, grandes regiões e unidades da federação. Rio de Janeiro: IBGE; 2015.

4. Guerra S, Sherrill DL, Bobadilla A, Martinez FD, Barbee RA. The relation of body mass index to asthma, chronic bronchitis, and emphysema. Chest. 2002;122(4):1256-63.

5. Pelegrino NR, Faganello MM, Sanchez FF, Padovani CR, Godoy I. Relationship between body mass index and asthma severity in adults. J Bras Pneumol. 2007;33(6):641-6.

6. Vortmann M, Eisner MD. BMI and health status among adults with asthma. Obesity (Silver Spring). 2008;16(1):146-52.

7. Camargo CA Jr, Weiss ST, Zhang S, Willett WC, Speizer FE. Prospective study of body mass index, weight change, and risk of adult-onset asthma in women. Arch Intern Med. 1999;159(21):2582-8.

8. Lessard A, Turcotte H, Cormier $\mathrm{Y}$, Boulet LP. Obesity and asthma: a specific phenotype? Chest. 2008;134(2):317-23.

9. Arvaniti F, Priftis KN, Panagiotakos DB. Dietary habits and asthma: A review. Allergy Asthma Proc. 2010;31(2):e1-10.

10. Varraso R, Kauffmann F, Leynaert B, Le Moual N, Boutron-Ruault MC, Clavel-Chapelon F, et al. Dietary patterns and asthma in the E3N study. Eur Respir J. 2009;33(1):33-41.

11. McKeever TM, Lewis SA, Cassano PA, Ocké M, Burney P, Britton J, et al. Patterns of dietary intake and relation to respiratory disease, forced expiratory volume in $1 \mathrm{~s}$, and decline in 5-y forced expiratory volume. Am J Clin Nutr. 2010;92(2):408-15.

12. Lv N, Xiao L, Ma J. Dietary pattern and asthma: a systematic review and meta-analysis. J Asthma Allergy. 2014;7:105-21.

13. Lopes ACS, Caiaffa WT, Mingoti AS, Lima-Costa MFF. Ingestão alimentar em estudos epidemiológicos. Rev Bras Epidemiol. 2003;6(3):209-19.

14. Rosenkranz RR, Rosenkranz SK, Neessen KJJ. Dietary factors associated with lifetime asthma or hayfever diagnosis in Australian middle-aged and older adults: a crosssectional study. Nutr J. 2012;11:84.
15. Shi Z, Yuan B, Wittert GA, Pan X, Dai $Y$, Adams R, et al. Monosodium Glutamate Intake, Dietary Patterns and Asthma in Chinese Adults. PLoS One. 2012;7(12):e51567.

16. Barros R, Moreira A, Padrão $P$ Teixeira VH, Carvalho $P$, Delgado L, et al. Dietary patterns and asthma prevalence, incidence and control. Clin Exp Allergy. 2015;45(11):1673-80.

17. Global Initiative for Asthma. Global Strategy for Asthma Management and Prevention. Fontana (WI): GINA; 2015.

18. Pereira CA, Barreto SP, Simões JG, Pereira FW, Gerstler JG, Nakatani J. Valores de referência para espirometria em uma amostra da população brasileira adulta. J Pneumol. 1992;18(1):10-22.

19. Ellman MS, Viscoli CM, Sears MR, Taylor DR, Beckett WS, Horwitz RI. A new index of prognostic severity for chronic asthma. Chest. 1997;112(3):582-90.

20. Pinheiro ABV, Lacerda EMA, Benzecry EH, Gomes MCS, Costa VM. Tabela para avaliação de consumo alimentar em medidas caseiras. 4th ed. São Paulo: Atheneu, 2000.

21. U.S. Department of Agriculture, Agricultural Research Service. USDA National Nutrient Database for Standard Reference, Release 25. Beltsville (MD): USDA; 2012. 
22. Hair JF Jr. Análise de agrupamentos. In: Hair JF Jr, Black WC, Babin BJ, Anderson RE, Tatham RL. Análise multivariada de dados. 5th ed. Porto Alegre: Bookman; 2005. p. 380-419.

23. Bakolis I, Hooper R, Thompson RL, Shaheen SO. Dietary patterns and adult asthma: population-based case-control study. Allergy. 2010;65(5):606-15.

24. Hooper R, Heinrich J, Omenaas E, Sausenthaler S, Garcia-Larsen V, Bakolis I, et al. Dietary patterns and risk of asthma: results from three countries in European Community Respiratory Health Survey-II. $\mathrm{Br}$ J Nutr. 2010;103(9):1354-65.

25. Brasil, Ministério da Saúde, Secretaria de Vigilância em Saúde, Departamento de Vigilância de Doenças e Agravos não Transmissíveis e Promoção da Saúde. Vigitel Brasil 2014: Vigilância de fatores de risco e proteção para doenças crônicas por inquérito telefônico. Brasília, DF: Ministério da Saúde; 2015.

26. Lee SC, Yang YH, Chuang SY, Liu SC, Yang HC, Pan WH. Risk of asthma associated with energy-dense but nutrient-poor dietary pattern in Taiwanese children. Asia Pac J Clin Nutr. 2012;21(1):73-81.
27. Devereux G, Seaton A. Diet as a risk factor for atopy and asthma. J Allergy Clin Immunol. 2005;115(6):1109-17.

28. Bidad K, Anari S, Tavasoli S, Nazemi L, Moayeri H. Dietary intakes in asthmatic and non-asthmatic female pupils of Tehran. Acta Med Iran. 2011;49(7):468-71.

29. Gupta KB, Verma M. Nutrition and Asthma. Lung India. 2007;24(3):105-14.

30. Uddenfeldt M, Janson C, Lampa E, Leander M, Norbäck D, Larsson L, et al. High BMI is related to higher incidence of asthma, while a fish and fruit diet is related to a lower Results from a long-term follow-up study of three age groups in Sweden. Respir Med. 2010;104(7):972-80.

31. D'Innocenzo S, Matos SM, Prado MS, Santos CA, Assis AM, Cruz AA, et al. Dietary pattern, asthma, and atopic and non-atopic wheezing in children and adolescents: SCAALA study, Salvador, Bahia State, Brazil. Cad Saude Publica. 2014;30(9):1849-60.

32. Wood LG, Garg ML, Powell H, Gibson PG. Lycopene-rich treatments modify noneosinophilic airway inflammation in asthma: proof of concept. Free Radic Res. 2008;42(1):94-102.
33. Soutar A, Seaton A, Brown K. Bronchial reactivity and dietary antioxidants. Thorax. 1997;52(2):166-70.

34. La Vecchia C, Decarli A, Pagano R. Vegetable consumption and risk of chronic disease. Epidemiology. 1998;9(2):208-10.

35. Romieu I, Varraso R, Avenel V, Leynaert B, Kauffmann F, ClavelChapelon F. Fruit and vegetable intakes and asthma in the E3N study. Thorax. 2006;61(3):209-15.

36. Wood LG, Gibson PG. Dietary factors lead to innate immune activation in asthma. Pharmacol Ther. 2009;123(1):37-53.

37. Willers SM, Devereux G, Craig LC, McNeill G, Wijga AH, Abou ElMagd W, et al. Maternal food consumption during pregnancy and asthma, respiratory and atopic symptoms in 5-year-old children. Thorax. 2007;62(9):773-9.

38. Shaheen SO, Sterne JAC, Thompson RL, Songhurst CE, Margetts BM, Burney PGJ. Dietary Antioxidants and Asthma in Adults: Population-based Case-Control Study. Am J Respir Crit Care Med. 2001;164:1823-8. 